\title{
Comportamento ingestivo de novilhas de corte submetidas a estratégias de suplementação em pastagens de aveia e azevém
}

\section{Carolina Bremm¹, Marta Gomes da Rocha², Fabiana Kellermann de Freitas ${ }^{1}$, Stefani Macari1, Denise Adelaide Gomes Elejalde ${ }^{1}$, Dalton Roso ${ }^{1}$}

1 Programa de Pós-graduação em Zootecnia - UFSM.

2 Departamento de Zootecnia - UFSM.

RESUMO - Avaliou-se o comportamento ingestivo de novilhas de corte recebendo suplemento em pastagem de aveia preta (Avena strigosa Schreb.) e azevém (Lolium multiflorum Lam.) sob lotação contínua. Como tratamentos, foram avaliadas quatro estratégias de suplementação: sem suplemento - animais em pastagem de aveia (AV) e azevém (AZ); crescente - animais em pastagem de AV e AZ recebendo níveis crescentes de suplemento $(0,3 ; 0,6$ e $0,9 \%$ do peso vivo $\mathrm{PV}$ ); fixo - animais em pastagem de AV e AZ recebendo nível fixo de suplemento (0,9\% PV); e decrescente - animais em pastagem de AV e AZ recebendo níveis decrescentes (1,5;1,2 e 0,9\% do PV) de suplemento. As características estruturais (massa de forragem, massa de forragem verde, oferta de forragem, oferta de lâminas foliares verdes, relação folha:colmo, proporção de lâminas foliares e colmos + bainhas de aveia e proporção de lâminas foliares e colmos + bainhas de azevém) e bromatológicas (proteína bruta, digestibilidade in vitro da matéria orgânica, nutrientes digestíveis totais e fibra em detergente neutro) do pasto foram semelhantes entre as estratégias de suplementação, mas variaram conforme os períodos de utilização do pasto. Os tempos diários de pastejo, ruminação e ócio e de permanência no cocho (min/dia) e a massa de bocado (g MO/boc) diferiram entre as estratégias de suplementação e as características do pasto no decorrer do ciclo. A taxa de bocado/minuto foi influenciada apenas pelo ciclo do pasto.

Palavras-chave: farelo de trigo, lotação contínua, relação planta-animal-suplemento

\section{Ingestive behavior of beef heifers submitted to strategies of supplementation on oats and ryegrass pastures}

\begin{abstract}
It was evaluated the ingestive behavior of beef heifers on black oats (Avena strigosa Schreb.) and Italian ryegrass (Lolium multiflorum Lam.) pastures under different strategies of supplementation and continuous stocking system. The treatments evaluated were: 'no supplement'- animals on black oats (BO) and Italian ryegrass (IR) pasture; 'increasing' - animals on BO and IR pasture receiving increasing levels $(0.3,0.6$, and $0.9 \%$ of live weight - LW) of supplement; 'fixed' - animals on BO and IR pasture receiving $0.9 \%$ of LW of supplement; and 'decreasing' - animals on BO and IR pasture receiving decreasing $(1.5,1.2$, and $0.9 \%$ of $\mathrm{LW}$ ) levels of supplement. Structural sward characteristics (herbage mass, green herbage mass, herbage allowance, leaf blade allowance, leaf:stem ratio, and proportion of oats leaf blade and stem + sheath and proportion of ryegrass leaf blade and stem + sheath) and nutritive value (crude protein concentration, in vitro organic matter digestibility, total digestible nutrients, and neutral detergent fiber) were similar among strategies of supplementation and varied with pasture utilization periods. Daily grazing time, ruminating time, idling time, time spent near the trough (min/day), and bite mass (g OM/bite) varied with strategies of supplementation and sward characteristics. The biting rate/ min was influenced only by grazing cycle.
\end{abstract}

Key Words: plant-animal-supplement relation, set stocking system, wheat bran

\section{Introdução}

Decisões de manejo, como o período para expor novilhas de corte à reprodução, são complexas, pois são determinadas tanto por fatores biológicos quanto por fatores econômicos e suas interações. A suplementação para novilhas pode diminuir o risco da dependência exclusiva de pastagens anuais, como aveia (Avena strigosa) e azevém (Lolium multiflorum), que é maior quando o objetivo é o acasalamento destes animais aos 12-14 ou aos 18-20 meses, pois animais dessas categorias exigem nível alimentar alto e contínuo.

O ganho de peso médio diário dos animais em pastejo varia durante o ciclo da mistura de aveia e azevém, em

Este artigo foi recebido em 6/10/2006 e aprovado em 3/1/2008.

Correspondências devem serenviadas paramgdarocha@gmail.com. 
virtude da redução no consumo voluntário de forragem, tanto no início quanto no final da estação de pastejo (Rocha et al., 2007). A eficiência do uso de suplementos depende do efeito de sua ingestão no consumo de forragem. Assim, as chances de o suplemento aumentar o consumo total de MS e elevar o suprimento de nutrientes sem reduzir a utilização do pasto aumentam nos períodos inicial e final do pastejo (Rocha et al., 2007). Dois fatores afetam a ingestão de nutrientes quando bovinos em pastejo recebem concentrado: a taxa de substituição da forragem por concentrado e a redução da digestão de fibra (Rearte \& Pieroni, 2001). A taxa de substituição oscila com as mudanças estruturais e químicas do pasto. Valores de substituição elevados são indesejáveis para a rentabilidade do sistema, pois o custo do quilo de suplemento costuma ser superior ao custo do quilo de pasto.

O uso de um valor fixo de suplemento para animais em pastejo pode promover respostas biológicas e econômicas variáveis no decorrer do ciclo do pasto. Para verificar a economicidade das respostas biológicas ao uso de suplementos, seria necessário testar simultaneamente o uso de vários níveis de suplemento.

$\mathrm{O}$ fornecimento de concentrado geralmente altera o comportamento ingestivo (tempos de pastejo, ruminação e ócio, taxa e massa de bocado) de animais em pastejo (Krysl \& Hess, 1993). Animais sob suplementação percorrem diariamente maiores distâncias e escolhem melhor a forragem, portanto, são mais seletivos em comparação a animais mantidos exclusivamente em pastagem (Adams, 1985). Maior seletividade de lâminas foliares de azevém (Frizzo et al., 2003) e de partes da planta com menores teores de fibra em detergente neutro (Elejalde et al., 2004) foi observada em novilhas sob suplementação.

Este trabalho foi realizado para avaliar o efeito de quatro estratégias de suplementação sobre o comportamento ingestivo de novilhas de corte em pastagem de aveia preta e azevém.

\section{Material e Métodos}

O experimento foi realizado no Departamento de Zootecnia da Universidade Federal de Santa Maria, situada na Depressão Central do Rio Grande do Sul. O clima da região é do tipo Cfa (subtropical úmido), segundo a classificação de Köppen (Moreno, 1961). A área experimental pertence à Unidade de Mapeamento São Pedro e apresenta solo classificado como Argissolo Vermelho Distrófico arênico (EMBRAPA, 1999). De acordo com os resultados da análise, o solo da área experimental possui as seguintes características (valores médios): $\mathrm{pH}-\mathrm{H} 2 \mathrm{O}: 5$,2; índice SMP: 5,6; \% argila: 26 m/V; P: 12,0 mg/L; K: 94,2 mg/L; \% MO: 3,2 m/V; Al: 0,4 cmolc/L; Ca: 7,0 cmolc/L; Mg: 3,6 cmolc/L; saturação de bases: 70\%; e saturação de $\mathrm{Al}: 3 \%$.

A pastagem de aveia-preta (Avena strigosa Schreb.) e azevém (Lolium multiflorum Lam.) foi estabelecida pelo sistema de plantio direto nos dias 8 e 9 de maio de 2003, pelo método de preparo mínimo, utilizando-se 100 e $50 \mathrm{~kg} / \mathrm{ha}$ de sementes de aveia-preta e azevém, respectivamente. Foram utilizados $250 \mathrm{~kg} / \mathrm{ha}$ de adubo da fórmula 07-10-10 (N-P-K) como adubação de base e $127 \mathrm{~kg} /$ ha de nitrogênio na forma de uréia, em cobertura, parcelados em três aplicações. A coleta de dados na pastagem foi realizada de 13 de julho a 1 de novembro de 2003, totalizando 112 dias.

Foram avaliadas quatro estratégias de suplementação: sem suplemento - animais exclusivamente em pastagem de aveia + azevém; crescente - animais em pastagem de aveia + azevém recebendo níveis crescentes de suplemento $(0,3$; 0,6 e $0,9 \%$ do peso vivo - PV) durante o ciclo do pasto; fixo - animais em pastagem de aveia + azevém recebendo mesmo nível de suplemento ( $0,9 \%$ do PV) durante o ciclo do pasto; e decrescente - animais em pastagem de aveia + azevém recebendo níveis decrescentes de suplemento $(1,5 ; 1,2 \mathrm{e}$ $0,9 \%$ do PV) durante o ciclo do pasto. A mudança no nível em crescente e decrescente foi realizada a cada 21 dias. Como suplemento utilizou-se farelo de trigo, fornecido diariamente às $14 \mathrm{~h}$ em cochos de madeira com $35 \mathrm{~cm}$ de acesso por animal. Os animais foram adaptados aos níveis de suplemento durante sete dias. $\mathrm{O}$ farelo de trigo fornecido aos animais apresentou 22,2\% de proteína bruta (PB), 70,4\% de digestibilidade in vitro da matéria orgânica (DIVMO), $65,5 \%$ de nutrientes digestíveis totais (NDT) e $42 \%$ de fibra em detergente neutro (FDN). Os animais tiveram livre acesso a água e sal comum nos piquetes.

As observações do comportamento ingestivo foram realizadas em oito piquetes com pastagem de aveia-preta e azevém, totalizando uma área de 7,7 hectares, com duas repetições de área por tratamento. Em cada unidade experimental, foram utilizadas três novilhas-teste, resultantes do cruzamento entre as raças Charolês e Nelore ( 8 meses de idade e $149 \mathrm{~kg}$ de peso inicial, em média) e um número variável de animais reguladores, conforme a necessidade de ajuste da carga animal. Utilizou-se sistema de lotação contínua com taxa de lotação variável (Mott \& Lucas, 1952).

Os animais foram identificados por meio de tatuagens e brincos numerados. Por ocasião das avaliações do comportamento, os animais-teste foram pintados para facilitar sua identificação. 
A massa de forragem (MF) pretendida foi de $1.200 \mathrm{a}$ $1.300 \mathrm{~kg} / \mathrm{ha}$ de matéria seca (MS) e foi determinada no início do período de pastejo e, posteriormente, a cada dez dias pela técnica de dupla amostragem. Em cada repetição, foram realizadas 20 estimativas visuais e cinco cortes rente ao solo, em quadrados de área de $0,25 \mathrm{~m}^{2}$. A forragem proveniente dos cortes foi homogeneizada e dividida em duas subamostras, uma para determinação do teor de MS do pasto e outra para separação botânica. Essas amostras foram pesadas e secas em estufa de ventilação forçada a $65^{\circ} \mathrm{C}$ por no mínimo 72 horas até peso constante. A determinação da composição botânica do pasto foi realizada por meio de separação manual dos componentes da amostra proveniente dos cortes em lâmina foliar de aveia, colmo + bainha de aveia, lâmina foliar de azevém, colmo + bainha de azevém e material morto. A relação folha:colmo (RFC) foi obtida pela divisão dos componentes lâmina foliar e colmo + bainha.

A massa de forragem multiplicada pela porcentagem de material verde no pasto (colmos + bainhas e lâminas foliares de aveia e azevém) resultou na massa de forragem verde (MFV). Para determinação da taxa de acúmulo diário de forragem (TAD), expressa em $\mathrm{kg} / \mathrm{ha}$, foram utilizadas três gaiolas de exclusão ao pastejo por repetição (Klingmann et al., 1943). A produção de matéria seca (PMS) foi obtida pela soma da MF inicial com o acúmulo de forragem do período experimental (TAD $\times$ número de dias).

A oferta de forragem (OF, $\mathrm{kg}$ de $\mathrm{MS} / 100 \mathrm{~kg}$ de PV) foi calculada dividindo-se a disponibilidade diária de forragem $(\mathrm{MF} / 21$ dias + TAD) pela carga animal média do período (CA, $\mathrm{kg} / \mathrm{ha}$ de PV). Utilizando-se a MF, a carga animal utilizada em cada período de avaliação e a porcentagem de lâmina foliar no pasto nos períodos de avaliação, calculou-se a oferta de lâminas foliares verdes (OLFV), em kg de MS/100 kg de PV. As perdas de forragem (PRD) foram determinadas por meio da metodologia proposta por Hillesheim (1987).

A determinação da composição bromatológica da forragem aparentemente consumida pelos animais foi feita em análise laboratorial de amostras de forragem colhidas por meio de simulação de pastejo (Euclides et al., 1992). A amostra colhida foi pesada e seca em estufa de ventilação forçada a $65^{\circ} \mathrm{C}$ por 72 horas. Depois, foi triturada em moinho tipo Wiley e encaminhada para análise. Os parâmetros avaliados foram: PB, DIVMO e FDN, de acordo com as técnicas descritas pela AOAC (1984), Tilley \& Terry (1963) e Goering \& Van Soest (1970). O teor de NDT foi obtido pelo produto entre a porcentagem de matéria orgânica (\%MO) e a digestibilidade in vitro da matéria orgânica (\%DIVMO) dividido por 100 (Barber et al., 1984).

As avaliações do comportamento ingestivo foram feitas em três períodos contínuos de 24 horas, respectiva- mente, nos dias 28 e 29 de julho, 13 e 14 de agosto e 26 e 27 de agosto, de modo que cada avaliação correspondeu a um período de pastejo. As temperaturas médias nestas datas foram de 18,$3 ; 16,4 \mathrm{e} 9,5^{\circ} \mathrm{C}$. Foram utilizados oito avaliadores, que revezaram em plantões de 4 horas, ficando um observador responsável pela observação dos animais-teste de dois piquetes. As anotações foram feitas a cada dez minutos, por meio de observação visual (Jamieson \& Hodgson, 1979a), para registro das atividades de pastejo, ruminação, ócio e permanência no cocho. O tempo gasto pelos animais na seleção e apreensão da forragem, incluindo os curtos espaços de tempo utilizados no deslocamento para a seleção da dieta, foi considerado tempo de pastejo (TP) (Hancock, 1953). O tempo de ruminação (TR) foi identificado por meio da cessação do pastejo e da realização da atividade de mastigação. O tempo de ócio (TO) correspondeu ao período no qual o animal permaneceu em descanso (Forbes, 1988) e o tempo de permanência no cocho (TC), ao tempo despendido pelo animal ao consumo de suplemento e à permanência no local onde era fornecido o suplemento.

$\mathrm{O}$ desaparecimento de forragem (DF, $\mathrm{kg} / \mathrm{ha} \mathrm{MS}$ ) foi calculado pela equação DF = PMS - MF final - PRD e, dividido pelo número de dias do período, resultou no DF diário. O valor encontrado foi dividido pela CA média, multiplicado por 100 e denominado consumo diário de forragem, expresso em \% do PV.

Durante os mesmos períodos de avaliação do comportamento animal, quando os animais estavam em atividade de pastejo, foi registrada, a cada dez minutos, a taxa de bocado (TXBOC) dos animais-teste de cada tratamento, estimada por meio do tempo gasto pelo animal para realizar 20 bocados (Hodgson, 1982). Para o cálculo da massa de bocado (MBOC), dividiu-se o consumo diário de forragem pelo total de bocados diários (taxa de bocado $\times$ tempo de pastejo; Jamieson \& Hodgson, 1979b).

O delineamento experimental utilizado foi inteiramente casualizado, com medidas repetidas no tempo, com duas repetições de área por tratamento e três animais-teste por repetição. $\mathrm{O}$ modelo matemático referente à análise dos parâmetros estimados foi:

$$
\mathrm{Y}_{\mathrm{ijk}}=\mu+\mathrm{NS}_{\mathrm{i}}+\mathrm{P}_{\mathrm{j}}+\mathrm{R}_{\mathrm{k}}(\mathrm{NS})_{\mathrm{i}}+(\mathrm{NS} * \mathrm{P})_{\mathrm{ij}}+\sum_{\mathrm{ijk}},
$$
em que $Y_{i j k}=$ variáveis dependentes; $\mu=$ média de todas as observações; $\mathrm{NS}_{\mathrm{i}}=$ efeito do i-ésimo nível de suplementação; $\mathrm{P}_{\mathrm{j}}=$ efeito do $\mathrm{j}$-ésimo período; $\mathrm{R}_{\mathrm{k}}(\mathrm{NS})_{\mathrm{i}}=$ efeito da $\mathrm{k}$-ésima repetição dentro do i-ésimo nível de suplementação (erro A); $N S * P_{i j}=$ efeito de interação i-ésimo nível de suplementação $\times$ j-ésimo período; $\sum_{\mathrm{ijk}}=$ erro experimental (erro B).

Os dados foram submetidos à análise de variância e ao teste $\mathrm{F}$ a $5 \%$ de significância utilizando-se o procedimento MIXED e, quando detectadas diferenças, as médias foram 
comparadas pelo teste t de Student (PDIFF). As variáveis foram estudadas por meio do programa estatístico Statistical Analysis System (SAS, 2001).

\section{Resultados e Discussão}

Não houve interação níveis de suplemento $\times$ períodos para as variáveis relacionadas ao pasto $(\mathrm{P}>0,05)$. Os valores médios de massa de forragem, massa de forragem verde, altura, oferta de forragem, oferta de lâminas foliares verdes, relação folha:colmo, lâmina foliar de aveia, colmo + bainha de aveia, lâmina foliar de azevém, colmo + bainha de azevém, teor de proteína bruta, digestibilidade in vitro da matéria orgânica, nutrientes digestíveis totais e fibra em detergente neutro nos períodos de utilização do pasto não foram influenciados $(\mathrm{P}>0,05)$ pelos níveis de suplemento (Tabela 1).

As variáveis $\mathrm{MF}, \mathrm{MFV}$ e OF foram semelhantes entre os períodos de pastejo $(\mathrm{P}>0,05)$ e a MFV representou, em média, $85,7 \%$ da MF. Com o decorrer dos períodos de utilização do pasto, as proporções de lâminas foliares e colmos + bainhas de aveia diminuíram $(\mathrm{P}<0,05)$. A proporção de lâminas foliares de aveia ao longo do período de pastejo foi, provavelmente, determinante do decréscimo da ALT $(\mathrm{P}<0,05)$ do pasto nos períodos e, também, dos maiores valores $(\mathrm{P}<0,05)$ de OLFV e RFC encontrados no início do período de pastejo. Nos dois períodos iniciais de pastejo, a proporção de azevém no pasto foi baixa, em torno de 3,5\% da MF. No período de 24/8 a 13/9, a proporção de azevém foi maior $(\mathrm{P}<0,05)$ que nos períodos anteriores e representou, em média, 4,8\% da MF. Houve variação na proporção de lâminas foliares nos períodos de pastejo, no entanto, a forragem selecionada pelos animais apresentou valores semelhantes de DIVMO, NDT e FDN $(\mathrm{P}>0,05)$. O teor médio de FDN foi 39\% inferior ao observado por Brustolin et al. (2005), utilizando as mesmas espécies forrageiras. O teor de PB da forragem aparentemente consumida pelos animais foi maior no período $3(\mathrm{P}<0,05)$ e pode estar associado ao aumento da população de azevém jovem nesse período. O teor médio de $\mathrm{PB}$ da forragem aparentemente consumida $(28,4 \%)$ é superior às exigências $(15,1 \%)$ para animais dessa categoria (NRC, 1996). Esta superioridade de $88,1 \%$ nas exigências favorece o uso de suplementos energéticos aos animais em pastejo para melhor equilíbrio da relação de carboidratos e nitrogênio na dieta (Lupatini et al., 1998). Poppi \& McLennan (1995) afirmam que níveis de proteína bruta superiores a $21 \%$ da matéria orgânica digestível ocasionam perdas de $\mathrm{N}$ na forma de amônia, em virtude do desbalanço entre a proteína e a energia degradável no rúmen.

Não houve interação $(\mathrm{P}<0,05)$ níveis de suplemento $\times$ períodos para massa de bocado (MBOC) e taxa de bocado (TXBOC). O valor médio de MBOC encontrado (Tabela 2) nas quatro estratégias de suplementação foi $46,7 \%$ inferior ao valor crítico de 0,300 g MO/bocado (Stobbs, 1973), o que provavelmente está relacionado ao método de obtenção do valor de MBOC, pois geralmente a massa de bocado determinada pelo consumo diário de forragem e pelo número total de bocados resulta em valor inferior à massa de bocado determinada pela coleta de extrusa (Forbes, 1988).

A massa de bocados diferiu entre as estratégias de suplementação $(\mathrm{P}<0,05)$ e foi maior na estratégia com nível crescente de suplementação. A maior MBOC pode ter sido ocasionada pelo maior consumo de lâminas foliares por bocado, pois este valor está relacionado principalmente à disponibilidade e acessibilidade de folhas no relvado

Tabela 1 - Características estruturais e bromatológicas da pastagem de aveia e azevém utilizada por novilhas de corte

\begin{tabular}{|c|c|c|c|c|}
\hline \multirow[t]{2}{*}{ Parâmetro } & \multicolumn{3}{|c|}{ Período de utilização } & \multirow[t]{2}{*}{ Média } \\
\hline & $13 / 7$ a $4 / 8$ & $5 / 8$ a $23 / 8$ & $24 / 8$ a $3 / 9$ & \\
\hline Massa de forragem, $\mathrm{kg} / \mathrm{ha}$ de $\mathrm{MS}$ & 1.173 & 1.189 & 1.332 & 1.231 \\
\hline Massa de forragem verde, $\mathrm{kg} / \mathrm{ha}$ de $\mathrm{MS}$ & 1.079 & 978 & 1.110 & 1.056 \\
\hline Altura, $\mathrm{cm}$ & $21,3 \mathrm{a}$ & $15,7 \mathrm{~b}$ & $14,4 \mathrm{c}$ & 17,2 \\
\hline Oferta de forragem, kg MS/100 kg PV & 8,7 & 6,8 & 8,2 & 7,9 \\
\hline Oferta de lâminas foliares verdes, $\mathrm{kg} \mathrm{MS} / 100 \mathrm{~kg} \mathrm{PV}$ & $5,3 \mathrm{a}$ & $3,1 \mathrm{~b}$ & $3,6 b$ & 4,0 \\
\hline Lâmina foliar de aveia, $\mathrm{kg} / \mathrm{ha}$ de MS & $353,5 \mathrm{a}$ & $142,7 b$ & $51,4 \mathrm{c}$ & 182,5 \\
\hline Colmo + bainha de aveia, kg/ha de MS & $292,4 \mathrm{a}$ & $233,2 \mathrm{ab}$ & $128,9 b$ & 218,2 \\
\hline Lâmina foliar de azevém, $\mathrm{kg} / \mathrm{ha}$ de MS & $28,5 b$ & $32,7 \mathrm{~b}$ & $39,8 \mathrm{a}$ & 33,7 \\
\hline Colmo + bainha de azevém, $\mathrm{kg} / \mathrm{ha}$ de MS & $8,1 \mathrm{~b}$ & $14,3 \mathrm{~b}$ & $23,2 \mathrm{a}$ & 15,2 \\
\hline Proteína bruta, \% & $26,3 b$ & $26,5 b$ & $32,3 \mathrm{a}$ & 28,4 \\
\hline Digestibilidade in vitro da matéria orgânica, \% & 60,1 & 61,4 & 63,9 & 61,8 \\
\hline Nutrientes digestíveis totais, \% & 54,0 & 56,0 & 58,2 & 56,1 \\
\hline
\end{tabular}

a, b na linha diferem entre si $(P<0,05)$. 
Tabela 2 - Médias de massa de bocado (g MO/bocado) e taxa de bocado (bocados/minuto) de novilhas de corte sob suplementação mantidas em pastagem de aveia e azevém

\begin{tabular}{lcccc}
\hline \multirow{2}{*}{ Tratamento } & \multicolumn{3}{c}{ Período de utilização } & \multirow{2}{*}{ Média } \\
\cline { 2 - 3 } & $13 / 7$ a $4 / 8$ & $5 / 8$ a $23 / 8$ & $24 / 8$ a $13 / 9$ & \\
\hline \multicolumn{4}{c}{ Massa de bocado $(\mathrm{g}$ MO/bocado) } \\
$\mathrm{SS}$ & 0,24 & 0,11 & 0,08 & $0,14 \mathrm{~b}$ \\
$\mathrm{C}$ & 0,29 & 0,13 & 0,17 & $0,20 \mathrm{a}$ \\
$\mathrm{F}$ & 0,17 & 0,10 & 0,08 & $0,12 \mathrm{~b}$ \\
$\mathrm{D}$ & 0,17 & 0,11 & 0,02 & $0,10 \mathrm{~b}$ \\
Média & $0,22 \mathrm{a}$ & $0,11 \mathrm{~b}$ & $0,09 \mathrm{~b}$ & 0,14 \\
\hline
\end{tabular}

Taxa de bocado (bocados/minuto)

$\begin{array}{lcccc}\text { SS } & 49,7 & 61,1 & 55,6 & 55,5 \\ \text { C } & 51,6 & 57,5 & 64,4 & 57,8 \\ \text { F } & 49,2 & 64,7 & 60,1 & 58,0 \\ \text { D } & 50,9 & 62,5 & 57,9 & 57,1 \\ \text { Média } & 50,4 \mathrm{~b} & 61,5 \mathrm{a} & 59,5 \mathrm{a} & 57,1\end{array}$

a, b diferem entre si $(\mathrm{P}<0,05)$.

SS - animais exclusivamente em pastejo; $C$ - animais recebendo níveis crescentes de suplemento $(0,3 ; 0,6 ; 0,9 \%$ do PV); F - animais recebendo nível fixo $(0,9 \%$ do $P V)$ de suplemento; $D$ - animais recebendo níveis decrescentes de suplemento $(1,5 ; 1,2 ; 0,9 \%$ do PV).

(Hodgson, 1990). A massa de bocado é a variável mais importante na determinação do consumo de animais em pastejo e a mais influenciada pela estrutura do dossel forrageiro (Hodgson, 1985). Assim, o aumento na dieta do nível de suplemento (12, 24 e 36\%), juntamente com as variações ocorridas na estrutura e composição do pasto (Tabela 1), pode ter proporcionado maior ingestão de lâminas foliares pelos animais.

Na média dos períodos, observou-se maior MBOC no início do período de pastejo $(\mathrm{P}<0,05)$, provavelmente em virtude da composição botânica (Arnold \& Dudzinsky, 1967), com predomínio de aveia, e da maior altura do pasto e largura da lâmina (Flores et al., 1993) (Tabela 1), proporcionando também menor taxa de bocados (Tabela 2).

A TXBOC foi semelhante entre as estratégias de suplementação $(\mathrm{P}>0,05)$, mas variou nos períodos de avaliação $(\mathrm{P}<0,05)$. Os maiores valores observados nos períodos 2 e 3 foram concomitantes com os menores valores de MBOC, pois, em geral, quando a massa de bocado diminui, aumenta a taxa de bocado, em virtude dos menores tempos de mastigação (Galli et al., 1996). O aumento no valor da TXBOC é um mecanismo que permite manter a taxa de consumo de forragem quando ocorrem variações no pasto que proporcionam menor massa de bocado. Essa variável é a de maior relevância no comportamento ingestivo e explica a maior porcentagem da variação no consumo diário de forragem, uma vez que a taxa de bocado e o tempo de pastejo têm papel secundário (Chacon \& Stobbs, 1976).
Houve interação $(\mathrm{P}<0,05)$ níveis de suplemento $\times$ períodos para TP, TR, TO e TC (Tabela 3). O TP dos animais mantidos na estratégia sem suplementação aumentou no decorrer dos períodos de pastejo $(\mathrm{P}<0,05)$, provavelmente em virtude das variações nos parâmetros ALT e FAV (Tabela 1). Quando os animais não recebem suplemento, o comportamento ingestivo depende exclusivamente das variações ocorridas na estrutura do pasto. No primeiro período, com a maior altura do pasto, os animais talvez tenham atingido o ponto de saciedade em menor tempo, em razão da maior velocidade de ingestão da forragem nessa situação (Carvalho \& Moraes, 2005), que reduz o TP. Nos períodos posteriores, com a redução na ALT e FAV, os animais utilizaram o aumento do tempo de pastejo como estratégia para aumentar o consumo (Newman et al., 1994). Segundo Carvalho et al. (2001), a estrutura do pasto é uma característica central e determinante tanto da dinâmica de crescimento e competição nas comunidades

Tabela 3 - Tempos de pastejo, ruminação e ócio e tempo de permanência no cocho de novilhas de corte sob suplementação em pastagem de aveia e azevém

\begin{tabular}{lll}
\hline Estratégia de & Período de utilização & Média \\
suplementação &
\end{tabular}
suplementação

$13 / 7$ a $4 / 8 \quad 5 / 8$ a $23 / 8 \quad 24 / 8$ a $13 / 9$

Tempo de pastejo $(\mathrm{min} / \mathrm{dia})$

\begin{tabular}{lcccc} 
SS & $393,3 \mathrm{c}$ & $461,6 \mathrm{~b}$ & $560,0 \mathrm{a}$ & 471,6 \\
$\mathrm{C}$ & $380,0 \mathrm{~b}$ & $486,6 \mathrm{a}$ & $356,6 \mathrm{~b}$ & 407,7 \\
$\mathrm{~F}$ & 386,6 & 385,0 & 415,0 & 395,5 \\
$\mathrm{D}$ & 401,6 & 380,0 & 453,3 & 411,6 \\
Média & 390,4 & 428,3 & 446,2 & 421,6 \\
\hline \multicolumn{4}{c}{ Tempo de ruminação $(\mathrm{min} / \mathrm{dia})$}
\end{tabular}

\begin{tabular}{lcccc} 
SS & $501,6 \mathrm{a}$ & $446,6 \mathrm{a}$ & $323,3 \mathrm{~b}$ & 423,8 \\
$\mathrm{C}$ & $439,9 \mathrm{~b}$ & $528,3 \mathrm{a}$ & $361,6 \mathrm{c}$ & 443,3 \\
F & $445,0 \mathrm{a}$ & $431,6 \mathrm{a}$ & $335,0 \mathrm{~b}$ & 403,9 \\
D & 455,0 & 451,6 & 440,0 & 448,8 \\
Média & 460,4 & 464,5 & 365,0 & 430,3 \\
\hline \multicolumn{4}{c}{ Tempo de ócio $(\mathrm{min} / \mathrm{dia})$}
\end{tabular}

\begin{tabular}{lcccc} 
SS & 545,0 & 531,6 & 551,6 & 542,7 \\
C & $588,3 \mathrm{a}$ & $391,6 \mathrm{~b}$ & $636,6 \mathrm{a}$ & 538,8 \\
$\mathrm{~F}$ & 588,3 & 580,0 & 594,9 & 587,7 \\
$\mathrm{D}$ & 553,3 & 568,3 & 491,6 & 537,7 \\
Média & 568,7 & 517,9 & 568,7 & 551,7 \\
\hline \multicolumn{4}{c}{ Tempo de permanência no cocho $(\mathrm{min} / \mathrm{dia})$}
\end{tabular}

\begin{tabular}{lcccc} 
SS & - & - & - & - \\
C & $31,7 \mathrm{~b}$ & $33,3 \mathrm{~b}$ & $86,6 \mathrm{a}$ & 50,5 \\
F & $31,6 \mathrm{~b}$ & $41,7 \mathrm{ab}$ & $55,0 \mathrm{a}$ & 53,9 \\
D & $21,7 \mathrm{c}$ & $43,3 \mathrm{~b}$ & $96,6 \mathrm{a}$ & 42,8 \\
Média & 28,3 & 39,4 & 79,4 & 49,0 \\
\hline
\end{tabular}

$a, b$ na linha diferem entre si $(P<0,05)$

$\mathrm{SS}$ - animais exclusivamente em pastejo; $\mathrm{C}$ - animais recebendo níveis crescentes de suplemento $(0,3 ; 0,6 ; 0,9 \%$ do PV); $F$ - animais recebendo nível fixo $(0,9 \%$ do $\mathrm{PV})$ de suplemento; $\mathrm{D}$ - animais recebendo níveis decrescentes de suplemento $(1,5 ; 1,2 ; 0,9 \%$ do PV). 
vegetais quanto do comportamento ingestivo dos animais em pastejo. O maior TP, de 24/8 a 13/9, ainda pode estar relacionado à maior procura por lâminas foliares novas de azevém, pois neste período observou-se maior teor de $\mathrm{PB}$ na forragem aparentemente consumida pelos animais (Tabela 1), resultado da maior proporção de azevém na dieta. Dessa forma, o menor TR observado neste período $(\mathrm{P}<0,05)$ poderia ter sido decorrente do maior consumo de lâminas foliares de azevém, embora o teor de FDN na forragem colhida pelos animais não tenha variado no tempo (Tabela 1).

O tempo de ócio (TO) foi semelhante nos períodos de pastejo $(\mathrm{P}>0,05)$, provavelmente por ser uma variável comportamental que pouco se altera em quaisquer condições de alimentação, pois nela estão incluídas atividades que não dependem do aspecto nutricional, como atividades de socialização e de termorregulação (Silveira, 2001).

O tempo de pastejo (TP) dos animais que receberam níveis crescentes de suplemento foi maior $(\mathrm{P}<0,05)$ no período 2, quando passaram a receber $0,6 \%$ do $\mathrm{PV}$ de suplemento. No período inicial de pastejo, a forragem constituía a maior parte da dieta dos animais experimentais. Dessa forma, o menor TP está relacionado às maiores proporções de lâminas foliares no pasto, principalmente de aveia (Tabela 1). No segundo e terceiro períodos, as lâminas foliares foram menos disponíveis, o que acarretaria provável aumento no TP, em razão do maior deslocamento à procura por lâminas foliares. Esse fato, no entanto, não foi observado no terceiro período, quando o suplemento foi fornecido aos animais em proporção de $0,9 \%$ do PV. Provavelmente, houve maior substituição do consumo do pasto pelo consumo de concentrado neste período, o que reduziu o TP (Patiño Pardo et al., 2003).

O tempo de permanência no cocho (TC) apresentou maior valor $(\mathrm{P}<0,05)$ neste período (24/8 a 13/9), concomitante com o maior nível de suplemento fornecido aos animais, o que sugere também a substituição do tempo destinado ao pastejo pelo consumo de concentrado. Essa substituição também pode ter sido determinante do menor TR observado, atribuído ao aumento no teor de amido na dieta (Dulphy et al., 1980). Bürger et al. (2000) também observaram que o aumento da participação de concentrado na dieta dos animais promoveu reduções no tempo de ruminação. O TR foi maior no período 2, pois o maior tempo de pastejo provavelmente proporcionou maiores quantidades de bolos alimentares e, conseqüentemente, maior tempo de ruminação. O TO foi menor $(\mathrm{P}<0,05)$ no período em que foram observados maiores TP e TR, provavelmente em virtude do caráter excludente das atividades diárias dos animais (Carvalho et al., 2001).
No nível fixo de suplemento, no qual os animais receberam farelo de trigo a $0,9 \%$ do $\mathrm{PV}$ durante todo o período experimental, o TP e TO foram semelhantes entre os períodos $(\mathrm{P}>0,05)$. Este nível correspondeu a $36 \%$ de concentrado na dieta total dos animais (NRC, 1996) e não foi influenciado pelas mudanças nas condições do pasto. O menor valor de TP foi observado no período $3(\mathrm{P}<0,05)$, quando o TC foi maior $(\mathrm{P}<0,05)$, e não diferiu do segundo período experimental. O menor tempo de ruminação pode ter sido ocasionado pelo maior tempo destinado ao consumo de suplemento pelos animais, considerando a excludência das atividades do repertório comportamental dos animais em pastejo.

Quando os animais receberam níveis decrescentes de suplemento, o TP, TR e TO foram semelhantes nos períodos de utilização do pasto $(\mathrm{P}>0,05)$, uma vez que, nos três períodos de pastejo, 60 , 48 e $36 \%$ da dieta total dos animais foi constituída de concentrado $(1,5 ; 1,2$ e $0,9 \%$ do PV). O TC, no entanto, aumentou com a redução no nível de suplemento fornecido aos animais $(\mathrm{P}<0,05)$, fato que pode estar relacionado à maior competição pelo suplemento à medida que se reduziu a proporção de suplemento na dieta dos animais, fazendo com que permanecessem mais tempo próximos ao cocho.

\section{Conclusões}

O comportamento ingestivo de novilhas de corte em pastagem de aveia e azevém varia de acordo com as estratégias de suplementação e as características do pasto. O comportamento ingestivo de animais mantidos exclusivamente em pastejo é mais suscetível às variações nas características do pasto que o comportamento ingestivo de animais sob suplementação. Fornecer níveis crescentes de suplemento ao longo do período de pastejo é uma estratégia de manejo desejável, pois promove aumento da massa de bocado, principal componente do comportamento ingestivo determinante do consumo.

\section{Literatura Citada}

ADAMS, D.C. Effect of time of supplementation on performance, forage intake and grazing behavior of yearling beef grazing Russian roildrygrass in the fall. Journal of Animal Science, v.61, n.4, p.1037-1042, 1985 .

ANUALPEC. Anuário da Pecuária brasileira. São Paulo: FNP Consultoria \& Comércio, 2006. 369p.

ARNOLD, G.W.; DUDZINSKY, M.L. Studies on the diet of grazing animals: III. The effect of pasture species and pasture structure on the herbage intake of sheep. Australian Journal of Agriculture Research, v.18, p.657-666, 1967.

ASSOCIATION OF OFFICIAL ANALYTICAL CHEMISTS AOAC. Official methods of analysis. 14.ed. Washington, D.C.: 1984. 1141p. 
BARBER, W.P.B.; ADAMSON, A.H.; ALTMAN, J.F.B. New methods of feed evaluation. In: HARESIGN, W.; COLE, D.J.A. (Eds.) Recent advances in animal nutrition. London: Butterworths, 1984. p.161-176.

BRUSTOLIN, K.D.; QUADROS, F.L.F.; VIÉGAS, J. et al. Recria de bezerros em pastagem de aveia e azevém utilizando suplementação energética com níveis de promotor de crescimento. Ciência Rural, v.35, n.2, p.428-434, 2005

BÜRGER, P.J.; PEREIRA, J.C.; QUEIROZ, A.C. et al. Comportamento ingestivo em bezerros holandeses alimentados com dietas contendo diferentes níveis de concentrado. Revista Brasileira de Zootecnia, v.29, n.1, p.236-242, 2000.

CHACON, E.; STOBBS, T.H. Influence of progressive defoliation of a grass sward on the eating behavior of cattle. Australian Journal of Agriculture Research, v.7, n.3, p.709-727, 1976

CARVALHO, P.C.F.; MORAES, A. Comportamento ingestivo de ruminantes: bases para o manejo sustentável do pasto. In: MANEJO SUSTENTÁVEL EM PASTAGEM, 1., 2005, Maringá. Anais... Maringá, 2005. (CD-ROM)

CARVALHO, P.C.F; RIBEIRO FILHO, H.M.N; POLI, C.H.E.C. et al. Importância da estrutura da pastagem na ingestão e seleção de dietas pelo animal em pastejo. REUNIÃO ANUAL DA SOCIEDADE BRASILEIRA DE ZOOTECNIA, 38., 2001, Piracicaba. Anais... Piracicaba: Fundação de Estudos Agrários Luiz de Queiroz, 2001. p.853-871.

DULPHY, J.P.; REMOND, B.; THERIEZ, M. Ingestive behavior and related activities in ruminants. In: RUCKEBUSCH, Y.; THIVEND, P. (Ed.) Digestive physiology and metabolism in ruminants. Lancaster: MTP, 1980. p.103-122.

ELEJALDE, D.A.G.; ROCHA, M.G.; PIRES, C.C. et al. Parâmetros de qualidade da pastagem de azevém "Lolium multiflorum Lam." aparentemente consumida por ovelhas de descarte. In: REUNIÓN DEL GRUPO TÉCNICO REGIONAL DEL CONO SUR EN MEJORAMIENTO Y UTILIZACION DE LOS RECURSOS FORRAJEROS DEL AREA TROPICAL E SUBTROPICAL Grupo Campos, 20., 2004, Salto - Uruguai. Palestras... Salto: Reunión del Grupo Técnico Regional del Cono Sur, 2004. p.336-337.

EMPRESA BRASILEIRA DE PESQUISA E AGROPECUÁRIA EMBRAPA. Centro Nacional de Pesquisa de Solos. Sistema brasileiro de classificação de solos. Brasília; Rio de Janeiro: 1999. 412p.

EUCLIDES, V.P.B.; MACEDO, M.C.M.; OLIVEIRA, M.P. Avaliação de diferentes métodos de amostragem sob pastejo. Revista Brasileira de Zootecnia, v.21, n.4, p.691-702, 1992.

FLORES, R.E.; LACA, E.A.; GRIGGS, C. et al. Sward height and vertical morphological differentiation determine cattle bite dimensions. Agronomy Journal, v.85, n.3, p.527, 1993.

FORBES, T.D.A. Researching the plant-animal interface: the investigation of ingestive behavior in grazing animals. Journal of Animal Science, v.66, p.2369-2379, 1988.

FRIZZO, A.; ROCHA, M.G.; RESTLE, J. et al. Produção de forragem e retorno econômico da pastagem de aveia e azevém sob pastejo com bezerras de corte submetidas a níveis de suplementação energética. Revista Brasileira de Zootecnia, v.32, n.3, p.632642, 2003.

GALLI, J.R.; CANGIANO, C.A.; FERNÁNDEZ, H.H. Comportamiento ingestivo y consumo de bovinos en pastoreo. Revista Argentina de Produção Animal, v.16, n.2, p.119-142, 1996.

GOERING, H.K.; Van SOEST, P.J. Forage fiber analysis (apparates, reagents, procedures and some applications). USDA Agricultural Research Service, 1970. (Handbook, 379).

HANCOCK, J. Grazing behaviour of cattle. Animal Breeding Abstract, v.21, n.1, p.1-13, 1953.

HILlESHEIM, A. Fatores que afetam o consumo e perdas de capim elefante (Pennisetum purpureum Schum.) sob pastejo. Piracicaba: Escola Superior da Agricultura Luiz de Queiroz, 1987. 94p. Dissertação (Mestrado em Zootecnia) Escola Superior da Agricultura Luiz de Queiroz, 1987.
HODGSON, J. Ingestive behavior. In: LEAVER, J.D. (Ed.) Herbage intake handbook. Hurley: British Grassland Society, 1982. p.113.

HODGSON, J. The control of herbage intake in the grazing ruminant. Proceedings of the Nutrition Society, v.44, p.339346, 1985.

HODGSON, J. Grazing management. Science into practice. England: Longman Scientific \& Technical, 1990. 203p.

JAMIESON, W.S.; HODGSON, J. The effect of daily herbage allowance and sward characteristics upon the ingestive behavior of calves under strip-grazing management. Grass and Forage Science, v.34, p.261-271, 1979a.

JAMIESON, W.S.; HODGSON, J. The effect of variation in sward characteristics upon the ingestive behavior and herbage intake of calves and lambs under continuous stocking management. Grass and Forage Science, v.34, p.273-281, 1979b.

KLINGMANN, D.L.; MILES, S.R.; MOTT, G.O. The cage method for determining consumption and yield of pasture herbage. Journal of Society of Agronomy, v.35, p.739-746, 1943.

KRYSL, L.J.; HESS, B.W. Influence of supplementation on behavior of grazing cattle. Journal of Animal Science, v.71, p.25462555,1993

LUPATINI, G.C.; RESTlE, J.; CERETTA, M. et al. Avaliação da mistura de aveia preta preta (Avena strigosa) e azevém (Lolium multiflorum) sob pastejo submetidas a níveis de nitrogênio. IProdução e qualidade de forragem. Pesquisa Agropecuária Brasileira, v.33, n.11, p.1939-11943, 1998.

MOREnO, J.A. Clima do Rio Grande do Sul. Porto Alegre: Secretaria da Agricultura, 1961. 41p.

MOTT, G.O.; LUCAS, H.L. The design, conduct, and interpretation of grazing trials in cultivated and improved pastures. In: INTERNATIONAL GRASSLAND CONGRESS, 6., 1952, State College. Proceedings... State College: Pennsylvania, State College Press. p.1380-1385.

NATIONAL RESEARCH COUNCIL - NRC. Nutrient requirement of beef cattle. 7.ed. Washington, D.C.: National Academy Press, 1996. 242p.

NEWMAN, J.A.; PARSONS, A.J.; PENNING, P.D. A note on the behavioral strategies used by grazing animals to alter their intake rates. Grass and Forage Science, v. 49, p. 502-505, 1994.

PATIÑO PARDO, N.M.; FISCHER, V.; BALBINOTTI, M. et al. Comportamento ingestivo diurno de novilhos em pastejo submetidos a níveis crescentes de suplementação energética. Revista Brasileira de Zootecnia, v.32, n.6, p.1408-1418, 2003.

POPPI, D.P.; McLENNAN, S.R. Protein and energy utilization by ruminants at pasture. Journal of Animal Science, v.73, n.1, p. 278-290, 1995.

REARTE, D.H.; PIERONI, G.A. Supplementation of temperate pastures. In: INTERNATIONAL GRASSLAND CONGRESS, 19., 2001, São Pedro. Proceedings... São Pedro: SBZ, 2001. p.679-689.

ROCHA, M.G.; PÖTTER, L.; ROSO, D. et al. Sistemas intensivos de produção de gado de corte - ênfase recria de fêmeas. In: CICLO DE PALESTRAS EM PRODUÇÃO E MANEJO DE BOVINOS, 12., 2007, Canoas. Palestras... Canoas: ULBRA, 2007. v.1, p.100-120.

STATISTICAL ANALYSIS SYSTEM - SAS. User's guide. Version 8.02. Cary: SAS Institute, 2001. (CD-ROM).

SILVEIRA, E.O. Comportamento ingestivo e produção de cordeiros em pastagem de azevém anual (Lolium multiflorum Lam.) manejada em diferentes alturas. Porto Alegre: Universidade Federal do Rio Grande do Sul, 2001. 154p. Dissertação (Mestrado em Zootecnia) - Universidade Federal do Rio Grande do Sul, 2001.

STOBBS, T.H. The effect of plant structure on the intake of tropical pastures. I. Variation in the bites size of the grazing cattle. Australian Journal of Agricultural Research, v.24, n.6, p.809-819, 1973.

TILLEY, J.M.A.; TERRY, R.A. A two-stage technique for the in vitro digestion of forage crop. Journal of British Grassland Society, v. 18, n.2, p.104-111, 1963. 